\title{
Forecasting Inflation: A Combination Approach
}

\author{
Martin M. Bojaj ${ }^{\text {*, Gordana Djurovic }}{ }^{2}$ \\ University of Montenegro, Faculty of Economics \\ Boulevard Jovana Tomasevica 37, 81000, Podgorica, Montenegro \\ E-mail.1*bmmbojaj@gmail.com (corresponding author); ${ }^{2}$ gordana@t-com.me
}

cross $^{\text {ref }}$ http://dx.doi.org/10.5755/j01.ee.31.2.24609

\begin{abstract}
The objective of this paper is to investigate and forecast the determinants of Montenegrin inflation empirically, using forecast combination methods, from January 2006 to December 2016, and out-of-sample 12-month horizon forecasting from January 2017 to December 2017. The main research problem is that given the struggle policymakers have had to define proper criteria to diagnose the onset of inflation indicators, we felt compelled to identify an approach and methodology that the government of Montenegro can use in the threshold to accessing the European Union. We examine three individual-predictor SVAR models to forecast inflation. Model 1 examines the internal determinants of inflation. Model 2 relates to demand-pull and cost-push variables. Model 3 examines external determinants. Combining the above three forecasts, we disclose two more RMSEs: equal and inverse MSE weights. Model 1 predicts inflation at $1.3 \%$, the inverse MSE at $1.5 \%$, and the weighted average at $1.4 \%$. They show forecasting performances that are sustainable and average inflation not more than $1.5 \%$ above the rate of the three best performing Member states: Cyprus (0.2\%), Ireland (0.3\%), and Finland (0.8\%) over the 12 months covering April 2017-March 2018. Our findings allow the policymakers to understand the factors involved in identifying the onset of inflation dynamics and inflation expectations in Montenegro better and develop more effective government regulations that can be employed nationally. In so doing, this research advances and recommends the toolset needed, combining forecasts, to combat the concerns of many macroprudential policymakers in Montenegro, especially the Central Bank of Montenegro.
\end{abstract}

Keywords: Macroeconometric Forecasting; Inflation; Forecast Combination; Impulse Response Functions; Inverse MSE Approach.

\section{Introduction}

The determinants of inflation are a critical question that macroeconomic policymakers in Montenegro have faced continually over the past decade, and particularly since 2002, following the adoption of the euro as Montenegro's formal currency. The country achieved the European Union candidate status in 2010 and has been in the process of negotiations since June 2012. Montenegro's present use of the euro will be addressed in the course of the final phase of the negotiations. Montenegro will participate in the economic and monetary union from accession as a Member State with a derogation and shall join the euro area following the Council decision to this effect based on an evaluation of its fulfillment of the necessary conditions (EU General Position, 2012).

Based on the requirements of the Maastricht criteria for entering the EU (European Commission, Convergence Report, 2018), the inflation rate must be stabilized as a prerequisite to joining. By opening the negotiations on Chapter 17 - Economic and monetary policy, the Union carefully monitors the progress in the alignment with and implementation of the acquis throughout the process of negotiating. One of the benchmarks for the chapter is: Montenegro has adopted the required constitutional change. It has to ensure that the primary objective of price stability is defined in compliance with Articles 127 (1) and 282 (2) of the Treaty on the Functioning of the European Union (Article 143 of the Constitution, 2012). To adopt the euro,
Montenegro has to bring its national legislation in line with the EU law and meet price stability to ensure economic convergence. Convergence criteria explicitly report: "A price-performance that is sustainable and average inflation not more than $1.5 \%$ above the rate of the three best performing Member States (European Commission, 2018)".

Even though inflation has been analyzed to a great extent, we find there is still sufficient space for enhancement. The novelty of this paper is that it uses a combined prediction for the economy of Montenegro. This paper suggests using high - dimensional dynamic models, examining time-series data from January 2006 to December 2017 for Montenegro. It evaluates and compares the empirical performance of various forecast combinations of inflation (Hendry \& Clements, 2001; Jore et al., 2010).

The objective is to reveal the determinants of inflation in Montenegro in the specified period and forecast the inflation dynamics, using a combination approach. To achieve that objective, we estimate recursively three structural VAR identified models of inflation. The first model identifies the primary internal and independent determinants of inflation (economic freedom and egovernment). Model 2 has demand-pull and cost-push variables (the nominal exchange rate, the demand, and private sector deposits as a measure of broad money, wages, and industrial production growth), while model 3 identifies the fundamental external and independent determinants of the supply shocks (oil and London Metal Exchange aluminum prices). We find that only one forecast 
combinations, the inverse MSE, outperforms all SVAR models. The theory of combining forecasts suggests that methods that weigh better-performing forecasts more heavily will perform better than the simple combination forecast (Stock \& Watson, 2004; Smith \& Wallis, 2009).

Ceteris paribus, our main statement is that we should incorporate aggregate determinants of inflation into the macro-econometric estimation. Forecast combinations are essential in the light of Montenegrin efforts to join the European Union.

\section{Literature Review}

Empirical inflation determinants are essential. Factors that determine inflation in advanced and transitional countries have been a topic of many empirical and theoretical studies (Golinelli \& Orsi, 2001; Egert, 2007; Blanchard et al., 2010; Koop \& Korobilis, 2012; Apostolov \& Josevski, 2016; Obradovic et al., 2017).

Papers that investigate Montenegrin inflation are limited. Articles that examined Montenegrin inflation highlighted that only the structural multidimensional models would accurately forecast inflation in Montenegro (Lipovina - Bozovic et al., 2015; Mitrovic - Mijatovic \& Ivanovic, 2017).

Lipovina - Bozovic et al., (2015) concluded that ARIMA forecasting models could not adequately predict inflation because of the existence of many external factors that influence the price movement in Montenegro. Mitrovic - Mijatovic and Ivanovic, (2017) found that openness of Montenegro, overheated demand in house prices, broad money, excise tax, and external shocks have a positive impact on inflation. International Monetary Fund, Montenegro-Article IV Consultation, (2018) emphasizes that a 2 p.p. VAT increase and excise increases adds approximately 1 p.p. to inflation.

Since there are only a small number of research papers that examine Montenegrin inflation, we have considered a large number of empirical studies on inflation determinants. Different methodologies and indicators are suggested to forecast inflation. Cecchetti et al., (2000), among other factors, highlights the impulse responses of the real economy to inflation. Dées and Güntner (2016), using a panel VAR approach, disentangle the role of unit labor costs and profit margins as the fundamental determinants of price dynamics across euro area countries.

Yi and Choi (2005) studied 207 countries from 19912007 and revealed that when internet penetration rate increases by $1 \%$, the inflation drops by $0.04 \%-0.13 \%$. Czernich et al., (2011) found a positive and significant relationship between broadband nexus and growth for OECD: from 1996-2007.

Acemoglu (2009) argues that there is convincing empirical support for the hypothesis that differences in economic institutions, rather than luck, geography, or culture, cause differences in incomes per-capita, hence inflation. The Heritage Foundation (2019) emphasizes: "In an economically free society, individuals are free to work, produce, consume, and invest in any way they please, with that freedom both protected by the state and unconstrained by the state." The positive relation between economic freedom (EF) and the endogenous growth model (EGM) have shown several studies (Berggren, 2003; Gwartney et al., 2004). Cebula (2011) showed a positive relationship between EF and EGM by using panel data. Hammermann and Flanagan (2007) conclude that greater liberalization would help reduce incentives for higher inflation based on 19-panel transition economies.

The technological progress speed $\left(A^{e}\right)$ and the dynamic pace of expectations that society and workers form is crucial with the shaping of price expectations $\left(P^{e}\right)$ as well, and the adjustment mechanism might get very complicated (Blanchard, 2017). Innovative technologies change the structure of the market, making old technology obsolete (Aghion \& Howitt, 2008). The decrease in employment in Montenegro's case might come from the fact that the demand for high-skilled workers is high, but the supply is low: increasing unemployment, impacting inflation.

Montenegro gave up the independent monetary policy. Inflation is indeed lower, especially in emerging markets, by some $4 \%$ when the central banks both de jure commits and de facto pegs the exchange rate rather than when it de facto pegs alone (Ghosh et al., 2014). Euroized countries should have very low pass-through inflation as their currencies are anchored to that of their principal trade partners (Del Cristo et al., 2012). Broad money clearly enters short-term inflation determinants (Lissovolik, 2003). Bobeica et al., (2019) show that it is more likely that labor costs are passed on to price inflation with demand shocks than with supply shocks.

Another strand of the literature that examines the timevarying effects of oil price shocks on the inflation dynamics are Kilian, (2009), Peersman and Van Robays, (2012), and Baumeister and Peersman, (2013). They show that the underlying sources of oil prices are critical determinants of inflation. Choi et al., (2017) find that a $10 \%$ increase in global oil prices, increases domestic inflation by about $0.4 \%$, being similar between advanced and developing countries.

The rising importance of governing inflation at the threshold of accessing the EU motivates the authors to conceptually and empirically research and predict inflation determinants.

\section{Methodology}

Even though inflation determinants have been studied to a great extent, we reveal a significantly wider knowledge gap. First, conceptual specification, based on which empirical examinations of inflation determinants are analyzed, is not prevailing combining theory and empirical analysis. Second, we identify recursively three structural VAR models and combine them with an equal and inverse MSE weighting approach. It has not been applied to Montenegrin inflation data. VARs turn out to be one of the key empirical tools in modern macroeconomics, and they allow one to model macroeconomic data informatively (Del Negro \& Schorfheide, 2011).

Here, we present parameter estimates and the main characteristics of the models. The first identified recursive SVAR model is as follows:

$$
\begin{aligned}
\pi_{t}= & \beta_{0}+\beta_{1} \log (E F)_{t}+\beta_{2} \log (E D G I)_{t}+\beta_{3} \text { CStock }_{t} \\
& +\beta_{4} \log (H)_{\mathrm{t}}+\beta_{5} E m p_{t}+\beta_{6} G D P_{-} G A P_{t}+u_{t}
\end{aligned}
$$


where $\pi_{t}$ denotes the inflation rate, $\log$ natural logarithm so that the inflation function has a constant price elasticity, $\log (E F)_{t}$ the natural logarithm of economic freedom, $\log (E D G I)_{t}$ the logarithmic state of technology, CStock $_{t}$ the capital stock rate, $\log (H)_{\mathrm{t}}$ the natural logarithm of human capital, $E m p_{t}$ the labor force, $G D P_{-} G A P_{t}$ denotes the gross domestic product gap. We will augment the growth model, which is represented in expression (1). Since Montenegro has set its national development strategy, it is valuable to analyze how this set of factors that determine economic growth dynamics impact inflation (ERP, 20182020). The debate among academics is what would be a proxy for the state of technological progress (Clarke \& Wallsten, 2004; Meijers, 2014). We will proxy it by egovernment development index (EGDI) in model 1. The EGDI incorporates the access characteristics, such as the infrastructure and educational levels, to reflect how a country is using information technologies to promote access and inclusion of its people (UN E-Government, 2019).

Model 2 will examine how changes in exchange rates, money supply, wages, and productivity impact inflation in Montenegro, using a recursive structural VAR approach. A complete monetary union in Europe is an essential intermediate step toward political union (Alesina and Grilli, 2000):

$$
\begin{gathered}
\pi_{t}=\beta_{0}+\beta_{1} \log (E X)_{t}+\beta_{2} \log (M 2)_{t}+\beta_{3} \log (W)_{t} \\
+\beta_{4} \operatorname{Prod}_{t}+u_{t}
\end{gathered}
$$

where $\log (E X)_{t}$ denotes the logarithmic form of the nominal exchange rate US dollar to euro, $\log (M 2)_{t}$ a measure of broad money defined by the International Monetary Fund (IMF), Monetary and Financial Statistics Manual (2017), $\log (W)_{t}$ logarithmic form of wages, and $\operatorname{Prod}_{t}$ denotes industrial production growth. Equation (2) incorporates both demand-pull and cost-push ingredients, starting from a balance between aggregate demand and aggregate supply.

Oil and aluminum prices are critical variables in model 3 , and we are interested in tracing their dynamics. Why? Because they are determined exogenously. These will indicate the shocks that come from the global market to the Montenegrin economy. The productivity growth engine of Montenegro substantially depends on export potential (Bogetic et al., 2013). Policy misalignment of Aluminum Plant Podgorica (KAP), caused the leading Montenegrin exporter to suffer. Bogetic et al., (2013) emphasize that Montenegro is not using the principal growth engine exports. Exports have transformed many small countries, especially those with significant location advantages. For 2007-2011, the exports-to-GDP ratio averaged only $39 \%$ in Montenegro, while in Slovenia 68\%, Estonia $78 \%$, and Malta $85 \%$ (Edgardo, 2008). It is projected that BAT technology will be invested in the amount of 50 million euros in the aluminum industry until 2030. It would reduce the greenhouse gas $(\mathrm{GHG})$ by $82.76 \%$ (impacting health and agriculture), and diversify products of aluminum (ERP, 2018-2020). Thus, oil and aluminum prices are significant determinants to be considered in the macro-econometric forecasting of the Montenegrin economy.

$$
\begin{gathered}
\pi_{t}=\beta_{0}+\beta_{1} \log (O i l)_{t}+\beta_{2} \log (\text { Alu })_{t}+\beta_{3} U n_{t} \\
+\beta_{4} G D P_{-} G A P_{t}+u_{t}
\end{gathered}
$$

where $\log (\mathrm{Oil})_{t}$ denotes the logarithmic form of the oil prices, $\log (A l u)_{t}$ the logarithm of LME aluminum prices, and $U n_{t}$ wages. This model estimates external innovations through oil and aluminum prices.

How can we pool, or combine these forecasts into an optimal forecast? Generally speaking, multiple forecasts are available to decision-makers before they make a policy decision. Given the uncertainty associated with identifying the true DGP, should a single (best) forecast be used? Or should we (somehow) average over all the available forecasts? It is implausible that one statistical model would be preferable to others at all forecast horizon points. Combining individual-predictor forecasts offers a simple way of building a sophisticated, more flexible forecasting model to explain the data.

A pooled - combined forecast is a weighted average of $Z$ forecasts (Zhang, 2019):

$$
\hat{y}_{T+h}^{c}=\sum_{i=1}^{Z} w_{T, h, i} x_{T, h, i}
$$

and choosing weights $w_{T, h, i}$, minimizes the risk associated with the loss from making a forecast error. The optimal weight for $x_{T, h, 1}$ is:

$$
w^{*}=\frac{\sigma_{T+h, 3}^{2}-\sigma_{T+h, 1,2,3}}{\sigma_{T+h, 1}^{2}+\sigma_{T+h, 2}^{2}+\sigma_{T+h, 3}^{2}-3 \sigma_{T+h, 1,2,3}}
$$

and more significant weight is assigned to the more precise model. The vector of optimal weights $w^{\prime}$ with $Z$ forecasts is:

$$
w^{\prime}=\frac{u^{\prime} \sum_{T, h}^{-1}}{u^{\prime} \sum_{T, h}^{-1} u}
$$

The squared bias and the forecast variance of the MSE loss function of a forecast is:

$$
\begin{gathered}
E\left[\left(y_{T+h}-x_{T, h, i}\right)^{2}\right] \\
=\sum_{i}^{Z} w_{T, h, i}^{2} \operatorname{bias}_{T, h, i}^{2}+\sigma_{y}^{2}+\sum_{i}^{Z} w_{T, h, i}^{2} \operatorname{Var}_{T, h, i}^{2} \\
\text { The recursive MSE of individual forecasts is: }
\end{gathered}
$$

$$
M S E_{T, h, i}=\frac{1}{T-h-1} \sum_{t=1}^{T-h}\left(y_{t+h}-x_{t, h, i}\right)^{2}
$$

Moreover, the MSE weights, relative performance weights, are:

$$
\omega_{T, h, i}=\frac{\frac{1}{M S E_{T, h, i}}}{\sum_{i=1}^{Z} \frac{1}{M S E_{T, h, i}}}
$$

Computing relative performance weights (inverse MSE) using either rolling windows or discounting allows more attention to be paid to recent performance. Combined forecasts imply diversification of risk.

\section{Empirical Results and Discussion}

All variables are stationary, $\mathrm{I}(0)$, based on unit root tests of ADF, PP, and KPSS stationarity test. Visual inspection and statistical correlograms portray and confirm stationarity as well. Test results of $t$-statistics and $p$-values reject the null hypothesis of unit-roots. Testing for potential structural breaks is crucial to identify for forecasting purposes as well as confidence bounds. Stability diagnostics, under recursive estimates - Chow breakpoint test - Quandt-Andrews - Bai- 
Perron, indicate there is a switch of parameters at a $5 \%$ significance level. Thus, we add dichotomous variables.

Recursively, we identify and estimate three SVAR models of inflation. For each of the criteria (AIC, LR, FPE, $\mathrm{SC}$, and HQ), a fitting lag length is suggested. We select two lags as the appropriate lag length for our VAR model 1 and three lags for models 2 and 3 (Clark and Ravazzolo, 2015).

As we can see from Figure 1, all the inverse roots of the characteristic polynomial lie within the unit circles, confirming the stationarity of the VAR model 1, 2, and 3.
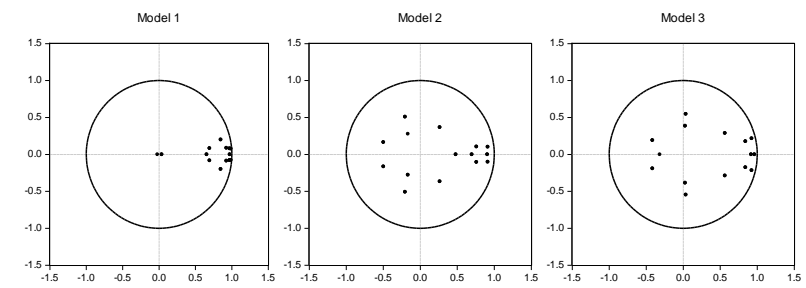

Figure 1. Inverse Roots of AR Characteristic Polynomials Source: Authors' estimates

The fan charts, in Figures 2-4, show the forecasting performance of each model. We portray results, showing ten confidence intervals: from $90 \%$ to the mode.

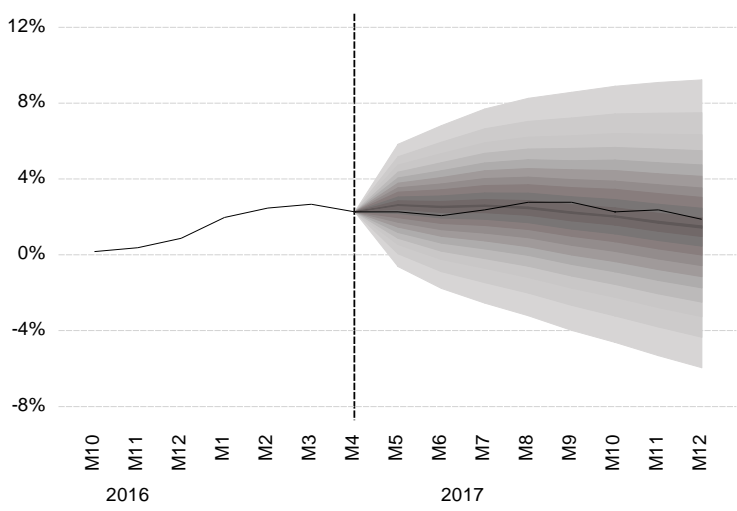

Figure 2. Fan Chart of Model 1 - Stochastic Simulator Source: Authors' estimates

Visual inspection reveals that the first model, in Figure 2 , fits the best into a $9 \%$ confidence band (from $1.6 \%$ to $2.0 \%$ inflation). It shows a forecasting performance that is sustainable and average inflation not more than $1.5 \%$ above the rate of the three best performing Member states: Cyprus $(0.2 \%)$, Ireland $(0.3 \%)$, and Finland $(0.8 \%)$. The average rate is $0.4 \%$ and, adding $1^{1 / 2}$ percentage points, the reference is $1.9 \%$ (EC, 2018).

Model 2, in Figure 3, has more oscillations around the mode than model 1. Still, model 2 has valuable information sets to be considered for combined forecasts. As expected, model 3, in Fig. 4, having the external shocks (oil and aluminum LME prices), creates more fluctuations as horizons increase.

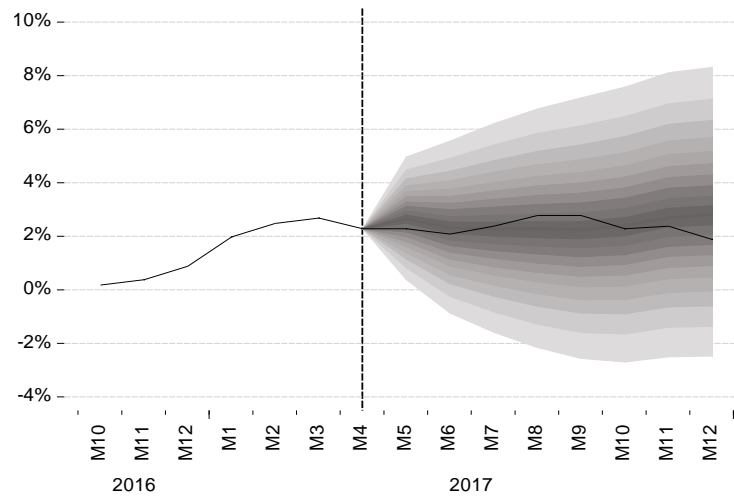

Figure 3. Fan Chart of Model 2 - Stochastic Simulator Source: Authors' estimates

In the second half of 2017, model 3 in Figure 4 fits into $72-81 \%$ confidence bands. We incorporate a certain number of variables within a model because adding more regressors to the forecasting model exacerbates the size problems (Clark \& West, 2006).

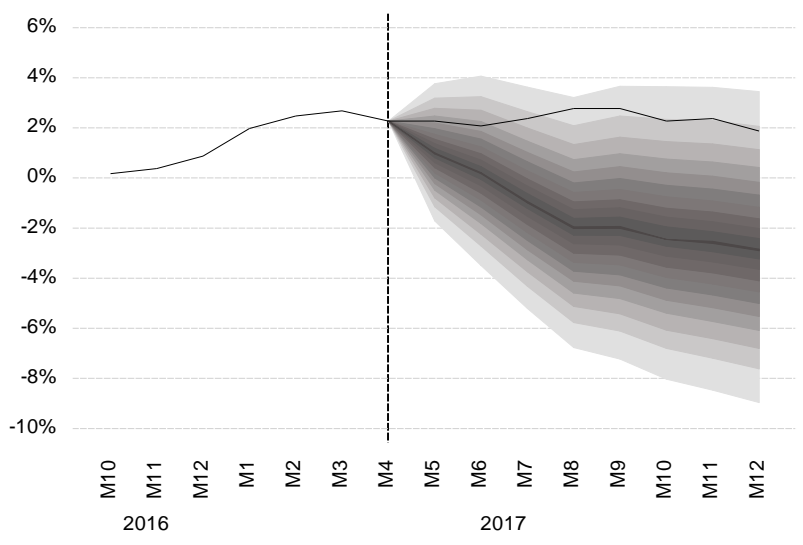

Figure 4. Fan Chart of Model 3 - Stochastic Simulator Source: Authors' estimates

We estimated three different models and then compared their forecast performance, based on root mean square error. Besides, we computed combined forecasts with these models. Are our combined forecasts better than the weighted sum of its parts? Each of the SVAR models has its explanatory variables and a $y$ variable. The three SVAR models have been specified, estimated, and examined which can forecast inflation the best.

We set the sample over which we want to estimate the models, from January 2006 to December 2016. We estimate each using least squares. The forecasting sample is from January 2017 to December 2017. Besides, the command of forecast(e) gives us evaluation statistics for each model, saving matrices. Running this part of the program (code), enables us to compare the forecasting ability of each model. Based on the RMSEs, we examine the forecast performances. The first model has the lowest root mean squared error (0.69), while the RMSE of the second model is (2.35). The RMSE of the third model appears to perform the worst, having a value of (3.71), as seen in Table 1.

Can we do better? Combining the above three forecasts, with equal weighting and relative performance weights (inverse MSE weights), reveals two more RMSEs. 
Forecast Evaluation Statistics of Model 1, 2, and 3

\begin{tabular}{lrrr}
\hline \hline Included observations: 12 & M1 & M 2 & M 3 \\
\hline \hline Root Mean Squared Error & $\mathbf{0 . 6 8 8 4}$ & $\mathbf{2 . 3 4 6 6}$ & $\mathbf{3 . 7 0 8 1}$ \\
Mean Absolute Error & 0.6175 & 2.0865 & 3.4428 \\
Mean Absolute P. Error & 25.842 & 90.341 & 145.0751 \\
Theil Inequality Coefficient & 0.1647 & 0.3364 & 0.9071 \\
\hline \hline
\end{tabular}

Source: Authors' estimates

The numerators of relative weights, based on inverse MSE, are as follows: $r \_1=2.11, r \_2=0.18$, and $r \_3=0.07$. While the value of the denominator is $r_{-} t=2.36$. By construction, the weights should sum up to 1 , and the relative weights are: $\mathrm{w}_{-} 1=0.89244, \mathrm{w}_{-} 2=0.076802$, and w_3 $=0.030758$.

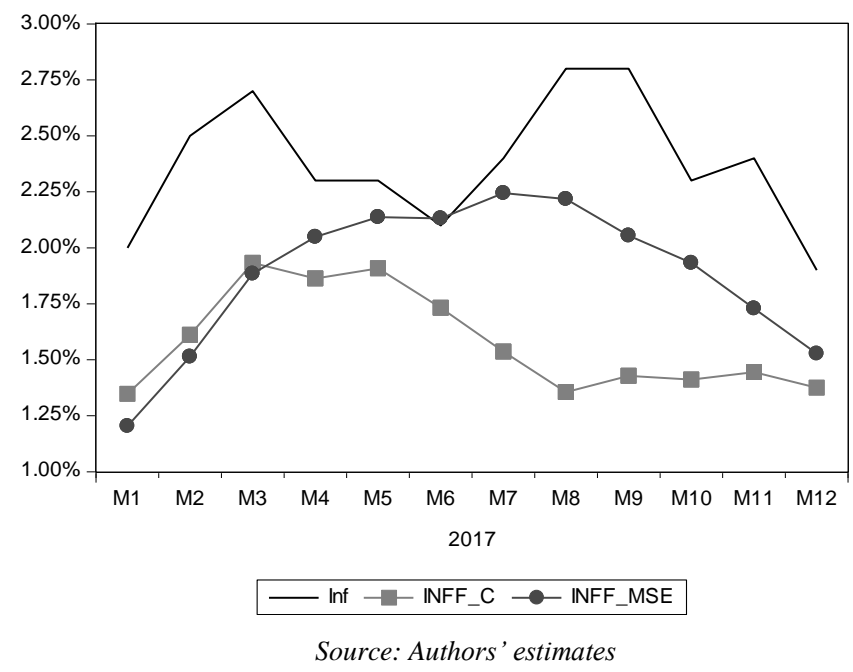

Figure 5. Combination Forecasts: Equal Weights and Inverse MSE Weights
Why are these results remarkable? They show that taking into consideration all determinants of inflation in the market of Montenegro reveals crucial information for the CBCG: better prediction. Even though the relative weights of model 2 and model 3 are relatively low, when combining into relative weights, they reveal vital and robust information for the macroprudential policymakers: a lower RMSE. Evidence is that adding variables, through SVAR models, systematically increases the forecasting performance, lowering the RMSE. We conclude that including adequate SVAR forecasts in the forecast combination consistently reduces the root mean square error of the combination forecasts. Suitably constructed forecast combinations in Montenegro should replace traditional judgemental inflation forecasts. Moreover, we find that in the first quarter, a simple average combination outperforms all performances. Besides, the performance of the relative weight stays very close even for the first quarter performance and is the least sensitive till December 2017. Traditionally, so far, inflation predictions have mainly been judgemental in Montenegro, making them difficult to replicate and justify. Low-dimensional models omit information contained in the other variables. Thus, combination forecasts, that pool individual-predictor forecasts, is the optimal solution for the Central Bank of Montenegro.

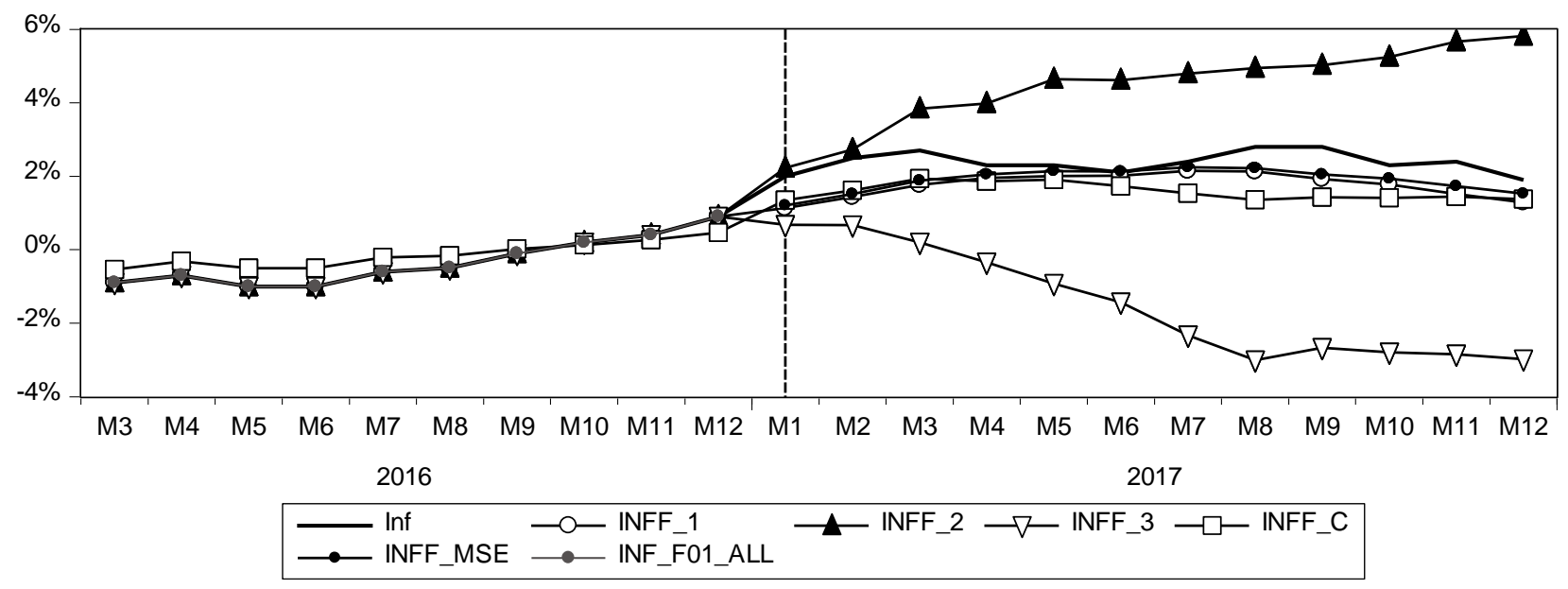

Figure 6. Forecast Comparison

Source: Authors' estimates

Figure 6 shows forecast comparison of the actual inflation (inf), inflation combined forecasts using relative weights based on inverse MSE (inff_mse), combined forecasts using equal weights (inff_c), combined forecast using mean square error-averaging of 5 forecasts (inf_f01_all), forecast using model 1 (inff_1), forecast using model 2 (inff_2), and forecast using model 3 (inff_3). The results are highlighting because, in the beginning, for the first three months, the simple arithmetic average combination forecast outperforms the more sophisticated 
"optimal" forecast composites. From April to December 2017, the inverse MSE is the optimal linear composite forecast, minimizing the mean-squared-error (MSE). Model 1 follows the inverse MSE closely to the end, but still, the average combination performs better than Model 2 and Model 3. At the end of December 2017, the actual inflation figures $1.9 \%$, while the inverse MSE $1.5 \%$, the averaging $1.4 \%$, model $1(1.3 \%)$, model $2(5.8 \%)$, and model $3(-3.0$ $\%)$. Models 1-3 show a forecasting performance that is sustainable and average inflation not more than $1.5 \%$ above the rate of the three best performing Member states: Cyprus $(0.2 \%)$, Ireland $(0.3 \%)$, and Finland $(0.8 \%)$. The average rate is $0.4 \%$ and, adding $1^{1 / 2}$ percentage points, the reference is $1.9 \%$ (EC, 2018).

Even though models 2 and 3 are way off compared to the actual inflation, incorporation of these variables is significant for the Central Bank of Montenegro (CBCG). The above results enable forecasters to address, evaluate, compare, and exploit the strength of using the highdimensional dynamic composite forecast models.

\section{Sensitivity Analysis}

The CBCG is interested to hypothetically see the reaction of inflation in different sensitive scenarios, such as an increase in the price of oil (external innovations) and economic freedom index-internal innovations (Groen et al., 2012). We consider them as leading indicators for inflation to which macroprudential policymakers should react in Montenegro. The alternative scene starts altering data from January 2016 till December 2017. Hypothetically, we increase oil prices from 0.5 to 2 points, respectively, from $14.01 \%$ to $48.43 \%$. What would be the impact of an increase in oil prices in the Montenegrin economy? The channel of oil price is multidimensional in Montenegro. It affects the production, consumers, government, investors, and Tax Administration of Montenegro (TAM).

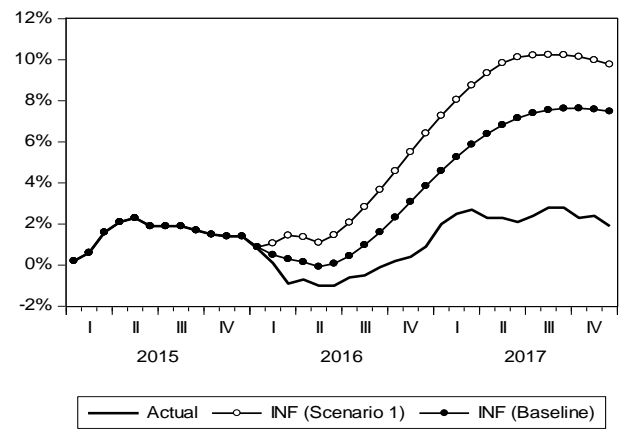

Figure 7. Inflation Deterministic - Dynamic Alternative Scenario of oil Price Increase

Source: Authors' estimates

The shock of an increase in oil prices might come endogenously as a result of fiscal consolidation. The cost of production increases by the increase of oil prices pushing companies to increase prices to keep in an existing margin of profit. In the case of oil prices increase, consumers do not have the same real value of money anymore. Their real wages decrease, leading to an increase in unemployment.

Having decided with fiscal consolidation and increasing the excise tax, the output gap decreases. It leads firms to increase their prices, causing inflation to increase. It is the turn of monetary policy through the CBCG to increase the interest rate to slow down the heating of inflation. The dynamics of decreasing output associated with increasing inflation is known as stagflation. In case the changes in oil prices (excise tax or stock market) in Montenegro are not accompanied by changes in expectations of inflation, then expectations will remain constant, and the Government will have a much easier job.

Is it to be anticipated that expectations will remain constant? What determines these expectations? If they have a strong belief in the stability of the macroeconomic environment, then their expectations will not swing. People form their expectations based on the era of information and knowledge, starting from the internet to brokers, news, banks, and other agents in the market worldwide (Giacomini, 2015).

The channel of economic freedom is multidimensional in Montenegro. The sensitive case scenario, in Figure 8, hypothetically increases the economic freedom index from $20 \%$ to $44 \%$ during the whole year of 2017 . The dynamic effects can be traced to inflation, as seen in Figure 8. We have to keep in mind that this is a deterministic simulation - dynamic solution forecasting performance, which uses forecasted lagged values to make a multi-period ahead forecasting. Thus, it automatically increases the chance of widening the probability for residuals. If we look at inflation, in Figure 9, the alternative sensitive scenario could deflate the prices from $0 \%$ to $-207 \%$.

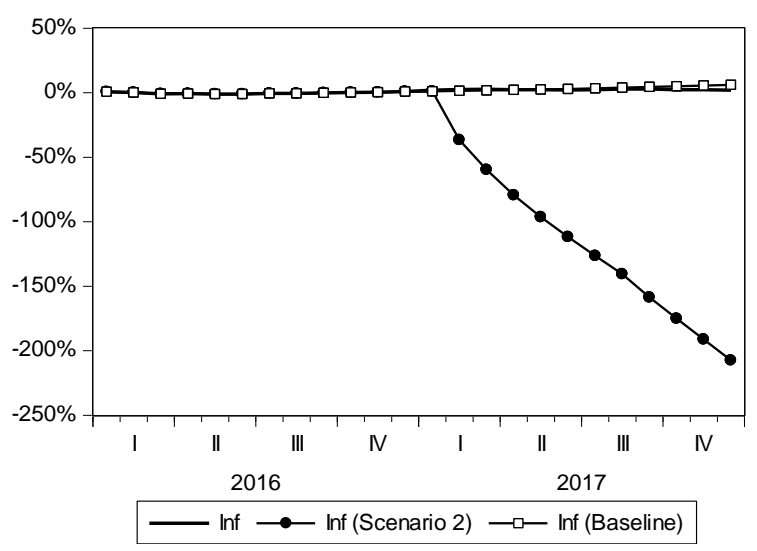

Figure 8: Deterministic Simulation - Dynamic Solution of Economic Freedom Alternative Scenario Source: Authors' estimates

Why did we use structural VARs? The CBCG is interested in tracing the effects of a shock to inflation. consider the event when Montenegro anticipates a rise in inflation. The CBCG increases the monetary policy interest rate, but inflation still rises, as expected. One could incorrectly conclude that the increase in interest rate led to a rise in inflation. The reaction was endogenous to the expected inflation. We must identify purely exogenous (policy or another type) shock to be able to trace out its dynamic effects: identify the structural VAR. Impulse responses trace the effects of structural shocks on the endogenous variables. Impulse response function will tell us the change in endogenous variables for each structural shock at $t, t+1$, and so on (Inoue \& Kilian, 2016). Using the 
same old relation between the forecast errors and structural shocks, Guerron-Quintana et al., (2017) emphasizes:

$$
X_{t}=\mu+A^{-1} u_{t}+\sum_{i=1}^{\infty} \psi_{i} A^{-1} u_{t-i}
$$

or more compactly:

$$
X_{t}=\mu+\sum_{i=1}^{\infty} C_{i} u_{t-i}
$$

$c_{11, i}$ and $c_{12, i}$ are the responses of $y$ and $x$ to a change in $u_{y t}$ and $u_{x t}$, respectively. Note that $c_{11,0}$ is the effect at impact, $c_{11,1}$ is the effect of $u_{y t}$ on $y$ and so on in succession:

$$
\frac{\partial y_{t+k}}{\partial u_{y t}}=C_{11, k}
$$

also, the cumulative effect is $\sum_{i=0}^{\infty} C_{11, i}$.

Since we examined three SVAR models, we will trace out the responses of inflation to one-unit standard deviation shocks of oil prices.

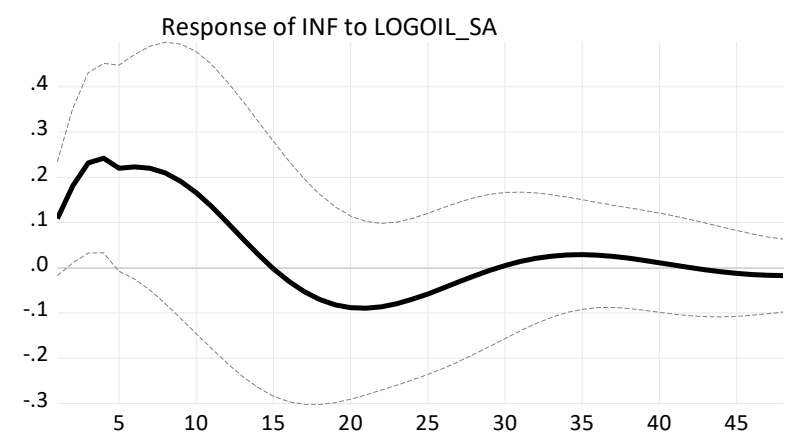

Figure 9. Impulse Responses to Oil Shocks Source: Authors' estimates

The inflation impulse response to Cholesky one standard oil price innovations starts increasing gradually after a lag of four months. Besides, it declines, reaching deflation of -0.002 after 15 months. It hits the bottom of 0.09 after 21 months. The transmission is evident. We should remember that an increase in oil prices cannot be a reaction to what is happening to the other variables. It must be exogenous. In this case, the "exogenous" movements of the Central Bank of Montenegro are exogenous. Thus, exogenous shocks were properly identified. In words: since the economy slowed down, output hits bottom after 13 months, while inflation after 21 months - a gap of 8 months between output and inflation hitting bottom. After only 30 months, inflation becomes positive, 0.0047 . The increase in the price of oil makes the CBCG and fiscal policymakers to intervene to lower inflation.

The oil price increase affected demand in the Montenegrin market, leading firms to change their investments and cancel projects. Within 12 months, while output decreases, inflation continues to increase. In this case, the fiscal policymakers in Montenegro intervened, adjusting the inflation and output. This adjustment process is mainly coordinated through the expectations process, which in Montenegro seems to be well done. This portrays a crucial point: the formation of expectations in Montenegro and the dynamic effects of shocks. The implication from this oil price shock is that output declines quickly for a transitional economy as Montenegro and takes more than a year to recover.
At the variance decomposition of inflation to oil shocks, most of the variance, in the first month, comes from itself $93.18 \%$. This is not a surprise. It results from our recursive ordering. At longer horizons-24 months, the contribution of shocks to variables to the movement, or forecast error variance, of the inflation increases as follows: oil (17.82\%), aluminum price $(11.41 \%)$, unemployment (13.62\%), and gdp_gap $1.14 \%$. The impact of oil price shock increases rapidly at the beginning, especially the first six months from $2.50 \%, 5.71 \%, 8.75 \%, 11.41 \%, 12.88 \%$, and $14.31 \%$, respectively.

In model 1, we noticed that economic freedom appears to be of crucial importance, and here we analyze the impulse responses and variance decomposition (Chan \& Jeliazkov, 2009; Chan, 2013). In Figure 10, inflation immediately starts to decline, especially in the first year, then somehow begins very slowly to increase. How can we interpret the above results? The good news is that the country is moving ahead towards the EU, being a member of NATO. Meanwhile, seeing economic reforms in the real market, it is to be expected from a forward-looking society to have a positive perspective. This implies a correction of price expectations $P^{e}$ in relation to the current price level $P$.

Finally, as expected, the Cholesky decomposition of forecast error variance of inflation to the economic freedom innovations is mostly the result of shocks to itself at short horizons $96.53 \%$. After six month-horizons, the contribution of economic freedom shocks to the movement of inflation increases to $9.13 \%$. At 12-month horizons, the contribution of economic freedom and its corresponding shocks to the evolution of inflation goes to $24.94 \%$. At $24-$ month horizons, the proportion of the movement of inflation due to shocks to economic freedom reaches $35.89 \%$. Response to Cholesky One S.D. (d.f. adjusted) Innovations \pm 2 S.E.

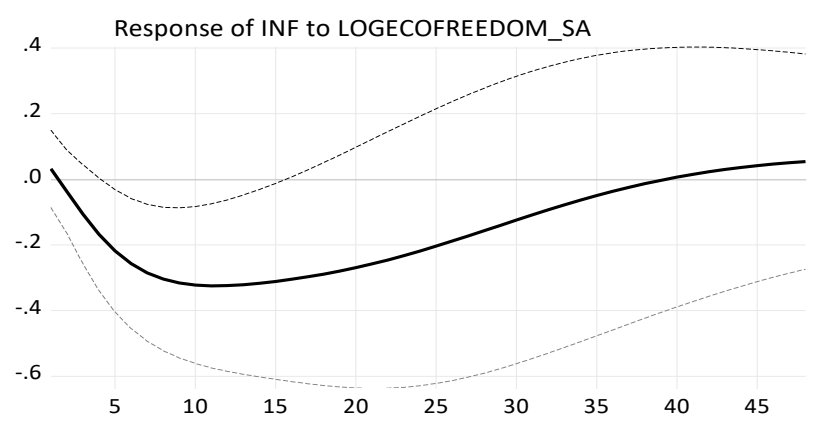

Figure 10. Impulse Responses to Economic Freedom Shocks Source: Authors' estimates

In conclusion, the contribution of economic freedom to the movements of inflation is powerful. In other words: in an economically free society, individuals are free to work, produce, consume, and invest.

\section{Conclusions and Implications}

Given the struggle policymakers have had to define proper criteria to diagnose the onset of inflation indicators, we felt compelled to identify an approach and methodology that the Government of Montenegro can use in developing anti-inflation and overall development strategy. Given the high increase in the interest of fulfilling the Maastricht 
convergence criteria and the lack of any uniform methodology, we believe that the findings presented in our paper will appeal to macroprudential policymakers. Although previous research papers have identified a few methods that could be used in forecasting inflation, such as internal and external variables, the methodologies developed from those findings have been restricted and difficult to administer on a national level. Thus, our findings will allow the policymakers to understand the factors involved in identifying the onset of inflation dynamics and inflation expectations in Montenegro better and develop more effective policy measures that can be used nationally. In so doing, we hope that our research paper advances the toolset needed to combat the concerns of many macroprudential policymakers in Montenegro, especially the Central Bank of Montenegro.

This paper reveals a significantly wider knowledge gap: both theoretical and empirical. We identified recursively three SVAR models. Each model aggregates critical macroeconomic variables to forecast inflation in Montenegro. The forecasting performance of model 1 predicts inflation at $1.3 \%$, the inverse MSE at $1.5 \%$, and the average weights at $1.4 \%$. They show a forecasting inflation performance that is sustainable and average inflation not more than $1.5 \%$ above the rate of the three best performing Member states: Cyprus (0.2\%), Ireland (0.3\%), and Finland $(0.8 \%)$. The average rate is $0.4 \%$ and, adding $1^{1 / 2}$ percentage points, the reference is $1.9 \%$.

We find that among the performance of the individualpredictor forecasts, model 1 performs the best, based on the root mean square error. It depends on current economic shocks and economic freedom. Model 1 performs even better than the combined equal weights, but the averaging performs better than individual model 2 and model 3. This essential evidence shows that economic freedom is critical in promoting sustainable growth. The main implications of this study suggest that economic freedom is crucial in governing inflation and sustainable growth in Montenegro.

Alternatively, we increased oil and economic freedom, and the forecasted inflation increases and sharply drops down, respectively: thus, implying that government regulations of economic activities are crucial. The impulse response findings reveal that the responses of inflation to a shock on oil and economic freedom are significant. The variance decomposition of inflation is moved mostly from economic freedom and oil prices.

In conclusion, the empirical findings of this paper provide macroprudential policymakers with an in-depth understanding of the forecast combination models.

\section{References}

Acemoglu, D. (2009). Introduction to Modern Economic Growth. Princeton: Princeton University Press.

Aghion, Ph. \& Howitt, P. (2008). The Economics of Growth, Cambridge, MA: MIT Press.

Alesina, A., \& Grilli, V. (2000). The European Central Bank: Reshaping Monetary Policy in Europe. National Bureau of Economic Research, Working Paper 7927.

Apostolov, M., \& Josevski, D. (2016). Aggregate Demand-Inflation Adjustment Model Applied to Southeast European Economies. Journal of Central Banking Theory and Practice, 5(1), 141-157. https://doi.org/10.1515/jcbtp-2016-0007

Baumeister, Ch., \& Peersman, G. (2013). Time-Varying Effects of Oil Supply Shocks on the US Economy, American Economic Journal: Macroeconomics, 5(4), 1-28. https://doi.org/10.1257/mac.5.4.1

Berggren, N. (2003). The Benefits of Economic Freedom: A Survey. The Independent Review, 8(2), $193-211$.

Blanchard, O., Dell'Ariccia, G., \& Mauro, P. (2010). Rethinking Macroeconomic Policy. Journal of Money, Credit and Banking, 42(1), 199-215. https://doi.org/10.1111/j.1538-4616.2010.00334.X

Bobeica, E., Ciccarelli, M., \& Vansteenkiste, I. (2019). The link between labor cost and price inflation in the euro area, European Central Bank, WP 2235.

Bogetic, Z., Pejovic, I., \& Osorio Roddarte, I. (2013). Expanding and Diversifying Montenegro's Exports: A Product Space Analysis. Journal of Central Banking Theory and Practice, 2, 19-34. https://doi.org/10.2139/ssrn.2288087

Cebula, R. J. (2011). Economic Growth, Ten Forms of Economic Freedom, and Political Stability. Journal of Private Enterprise, 26(2), 61-82.

Cecchetti, S. G., Chu, R. S., \& Steindel, Ch. (2000). The unreliability of inflation indicators, Current Issues in Economics and Finance, 6, 1-6.

Chan, J. C. C. (2013). Moving average stochastic volatility models with application to inflation forecast. Journal of Econometrics, 1760(2), 162-172. https://doi.org/10.1016/j.jeconom.2013.05.003

Chan, J. C. C., \& Jeliazkov, I. (2009). Efficient simulation and integrated likelihood estimation in state-space models. International Journal of Mathematical Modelling and Numerical Optimisation, 1, 101-120. https://doi.org/10. 1504/IJMMNO.2009.030090 
Choi, S., Furceri, D., Loungani, P., Mishra, S., \& Poplawski-Ribeiro, M. (2017). Oil Prices and Inflation Dynamics: Evidence from Advanced and Developing Economies. International Monetary Fund, WP/17/196. https://doi.org/10. 5089/9781484316658.001

Clark, T. E., \& West, K. D. (2006). Using out-of-sample mean squared prediction errors to test the martingale difference hypothesis. Journal of Econometrics, 135(1-2), 155-186. https://doi.org/10. 1016/j.jeconom.2005.07.014

Clark, T. E., \& Ravazzolo, F. (2015). Macroeconomic forecasting performance under alternative specifications of timevarying volatility. Journal of Applied Econometrics, 300(4), 551-575. https://doi.org/10.1002/jae.2379

Clarke, G. R. G., \& Wallsten, S. J. (2004). Has the Internet Increased Trade? Evidence from Industrial and Developing Countries. World Bank Policy Research Working Paper 3215. https://doi.org/10.1596/1813-9450-3215

Czernich, N., Falck, O., Kretschmer, T., \& Woessmann, L. (2011). Broadband Infrastructure and Economic Growth. The Economic Journal, 121(552) 505-532. https://doi.org/10.1111/j.1468-0297.2011.02420.X

Dees, S., \& Guntner, J. (2016). Forecasting Inflation Across Euro Area Countries and Sectors: A Panel VAR Approach. Journal of Forecasting, 36, 431-453. https://doi.org/10.1002/for.2444

Del Cristo, L.M.M., \& Gomez-Puig, M. (2012). Pass-through in Dollarized Countries: Should Ecuador Abandon the U.S. Dollar, Universitat de Barcelona, Research Institute of Applied Economics Working Paper, No.2012/16.

Del Negro, M., \& Schorfheide, F. (2011). Bayesian Macroeconometrics. In Handbook of Bayesian Econometrics, Chapter 7, 293-387. Oxford University Press. https://doi.org/10.1093/oxfordhb/9780199559084.013.0008

Edgardo, F. (2008). Small states, Smart Solutions: Increasing Connectivity and Effectiveness of Public Services, World Bank, Washington D.C.

Egert, B. (2007). Real Convergence, Price Level Convergence, and Inflation Differentials in Europe, CESifo Working Paper, No. 2127.

European Commission. (2018). Convergence Report. Institutional Paper 078, European Economy, ISSN 2443-8014 (online).

European Union. (2012). Consolidated version of the Treaty on the functioning of the European Union, Official Journal of the European Union, C 326/47.

European Union. (2012). General EU Position adopted by the Council, AD 23/12, CONF-ME-2, $13-14$.

Ghosh, A. R., Qureshi, M. S., \& Tsangarides, Ch. G. (2014). On the Value of Words: Inflation and Fixed Exchange Rate Regimes., IMF Economic Review, 62(2), 261-287. https://doi.org/10.1057/imfer.2014.14

Giacomini, R. (2015). Economic theory and forecasting: lessons from the literature. Econometrics Journal, 18, C22-C41. https://doi.org/10.1111/ectj.12038

Golinelli, R., \& Orsi, R. (2001). Modeling Inflation in EU Accession Countries: The Case of the Czech Republic, Hungary, and Poland, Ezoneplus, Working Paper No.9.

Government of Montenegro. (2018). Economic Reform Programme for Montenegro (ERP), 2018-2020.

Groen, J. J. J., Paap, R., \& Ravazzolo, F. (2013). Real-time inflation forecasting in a changing world. Journal of Business and Economic Statistics, 310(1), 29-44. https://doi.org/10.1080/07350015.2012.727718

Guerron-Quintana, P., Inoue, A., \& Kilian, L. (2017). Impulse response matching estimators for DSGE models. Journal of Econometrics, 196(1), 144-155. https://doi.org/10.1016/j.jeconom.2016.09.009

Gwartney, J. D., Holcombe, R. G., \& Lawson, R. A. (2004). Economic Freedom, Institutional Quality, and Cross-Country Differences in Income and Growth. Cato Journal, 24(3), 205-233.

Hammermann, F., \& Flanagan, M. (2007). What Explains Persistent Inflation Differentials Across Transition Economies?, Kiel Institute for the World Economy, Working Paper 1373. https://doi.org/10.5089/9781451867534.001

Hendry, D. F., \& Clements, M. P. (2002). Pooling of Forecasts, Econometrics Journal, 5, 1-26.

International Monetary Fund, (IMF). (2017). Monetary and financial statistics manual and compilation guide. Washington, DC: International Monetary Fund.

International Monetary Fund, (IMF). (2018). Montenegro: 2018 Article IV Consultation, IMF Country Report, No 18/121, Washington, D.C. https://doi.org/10.5089/9781484356968.002

Inoue, A., \& Kilian, L. (2016). Joint Confidence Sets for Structural Impulse Responses. Journal of Econometrics, 192, 421-342. https://doi.org/10.1016/j.jeconom.2016.02.008 
Jore, A. S., Mitchell, J., \& Vahey, S. P. (2010). Combining forecast densities from VARs with uncertain instabilities. Journal of Applied Econometrics, 250(4), 621-634. https://doi.org/10.1002/jae.1162

Kilian, L. (2009). Not All Oil Price Shocks Are Alike: Disentangling Demand and Supply Shocks in the Crude Oil Market. American Economic Review, 99(3), 1053-1069. https://doi.org/10.1257/aer.99.3.1053

Koop, G., \& Korobilis, D. (2012). Forecasting inflation using dynamic model averaging. International Economic Review, 530(3), 867-886. https://doi.org/10.1111/j.1468-2354.2012.00704.X

Lipovina-Bozovic, M., Cerovic, J., \& Vujosevic, S. (2015). Forecasting inflation in Montenegro using univariate time series models. BEH - Business and Economic Horizons, 11, 51-63. https://doi.org/10.15208/beh.2015.05

Lissovolik, B. (2003). Determinants of Inflation in a Transition Economy: The Case of Ukraine, International Monetary Fund, WP/03/126. https://doi.org/10.5089/9781451854923.001

Meijers, H. (2014). Does the internet generate economic growth, international trade, or both?. International Economics and Economic Policy, 11(1), 137-163. https://doi.org/10.1007/s10368-013-0251-X

Mitrovic-Mijatovic, M., \& Ivanovic, M. (2017). Inflation in a Fully-Euroised Economy: Could Inflation Differentials Threaten Competitiveness?. Journal of Central Banking Theory and Practice, 2, 101-124. https://doi.org/10.15 $15 /$ jcbtp-2017-0015

Obradovic, S., Sapic, S., Furtula, S., \& Lojanica, N. (2017). Linkage between Inflation and Economic Growth in Serbia: An ARDL Bounds Testing Approach. Inzinerine Ekonomika-Engineering Economics, 28(4), 401-410. https://doi.org/10.5755/j01.ee.28.4.14003

Peersman, G., \& Van Robays, I. (2012). Cross-country differences in the effects of oil shocks. Energy Economics, 34(5), 1532-1547. https://doi.org/10.1016/j.eneco.2011.11.010

Smith, J., \& Wallis, K. F. (2009). A Simple Explanation of the Forecast Combination Puzzle. Oxford Bulletin of Economics and Statistics, 71(3), 331-355. https://doi.org/10.1111/j.1468-0084.2008.00541.x

Stock, J. H., \& Watson, M. W. (2004). Combination Forecasts of Output Growth in a Seven-Country Data Set. Journal of Forecasting, 23(6), 405-430. https://doi.org/10.1002/for.928

The Heritage Foundation. (2019). Available from internet: https://www.heritage.org, accessed, October 31, 2019.

UN E-Government Knowledgebase. Available from internet: https://publicadministration.un.org, accessed, October 31, 2019.

Yi, M. H., \& Choi, Ch. (2005). The Effect of the Internet on Inflation: Panel Data Evidence. Journal of Policy Modeling, 27(7), 885-89. https://doi.org/10.1016/j.jpolmod.2005.06.008

Zhang, B. (2019). Real-time inflation forecast combination for time-varying coefficients models. Journal of Forecasting, 38(3), 175-191. https://doi.org/10.1002/for.2563

The article has been reviewed.

Received in November 2019; accepted in April 2020. 